\title{
Effects of tobacco smoke exposure during lactation on nutritional and hormonal profiles in mothers and offspring
}

\author{
A P Santos-Silva, E Oliveira, C R Pinheiro, A L Nunes-Freitas, Y Abreu-Villaça, A C Santana, \\ C C Nascimento-Saba, J F Nogueira-Neto ${ }^{1}$, A M Reis ${ }^{2}$, E G Moura and P C Lisboa
}

Department of Physiological Sciences, Roberto Alcantara Gomes Biology Institute, State University of Rio de Janeiro, Av. 28 de setembro, 87, Rio de Janeiro, RJ 20551-030, Brazil

${ }^{1}$ Laboratory of Lipids, School of Medicine, State University of Rio de Janeiro, Rio de Janeiro, 20551-030, Brazil

${ }^{2}$ Department of Physiology and Biophysics, Federal University of Minas Gerais, Belo Horizonte, Minas Gerais, 31270-901, Brazil

(Correspondence should be addressed to P C Lisboa; Email: pclisboa@uerj.br)

\begin{abstract}
Exposure to tobacco smoke is related to changes in energy balance regulation and several endocrine dysfunctions. Previously, we showed that maternal nicotine (the main addictive compound of tobacco) exposure exclusively during lactation affects biochemical profiles in mothers, milk, and pups. As the possible consequences for mothers and offspring of maternal smoking during lactation are still unknown, we evaluated the effects of tobacco smoke exposure on nutritional, biochemical, and hormonal parameters in dams and pups at weaning. After $72 \mathrm{~h}$ from birth, lactating rats were divided into two groups: smoke-exposed (S) in a cigarette-smoking machine, $4 \times 1 \mathrm{~h}$ per day throughout the lactation period without pups; control (C), rats were treated the same as the experimental group but exposed to filtered air. Dams and pups were killed at weaning (21 days of lactation). Body weight and food intake were evaluated. Milk, blood, visceral fat, adrenal,
\end{abstract}

and carcass were collected. S dams showed hyperprolactinemia $(+50 \%)$, hypoinsulinemia $(-40 \%)$, hypoleptinemia $(-46 \%)$, as well as lower triglycerides $(-53 \%)$ and very low-density lipoprotein cholesterol $(-50 \%)$. Milk of S dams had higher lactose $(+52 \%)$ and triglycerides $(+78 \%)$. S pups presented higher body protein $(+17 \%)$, lower total $(-24 \%)$ and subcutaneous fat contents $(-25 \%)$, hypoglycemia $(-11 \%)$, hyperinsulinemia $(+28 \%)$, hypocorticosteronemia $(-40 \%)$, lower adrenal catecholamine content $(-40 \%)$, hypertriglyceridemia $(+34 \%)$, higher high-density lipoprotein cholesterol $(+16 \%)$, and lower low-density lipoprotein cholesterol $(-45 \%)$. In conclusion, tobacco smoke exposure leads to changes in nutritional, biochemical, and hormonal parameters in dams and, passively through the milk, may promote several important metabolic disorders in the progeny.

Journal of Endocrinology (2011) 209, 75-84

\section{Introduction}

Globally, it is estimated that one-third of adults are regularly exposed to environmental tobacco smoke (ETS), and among them, $17 \%$ are women (WHO 2009). Smoking during pregnancy or lactation is a risk factor for the child's health since it is often associated with adverse effects such as ectopic pregnancy, spontaneous abortion, neurological abnormalities, fetal growth restriction, preterm delivery, and lower nutritional supply in the milk (Einarson \& Riordan 2009). Maternal exposure to ETS that contains a variety of toxic compounds is associated with low birth weight (Hegaard et al. 2006) and reduction of breastfeeding (Chou et al. 2007).

The progeny from smoking mothers show higher gastroenteritis episodes and more hospital admissions due to infections (Ladomenou et al. 2009) in childhood. Newborns from smoking mothers have lower leptin concentration in the cord blood (Mantzoros et al. 1997). Among compounds of tobacco smoke, nicotine is the most studied and the most addictive. Rats prenatally exposed to nicotine are heavier when compared to controls (Williams \& Kanagasabai 1984, Newman et al. 1999), suggesting that fetal nicotine exposure results in increased adiposity in the offspring.

Lactation is a critical period of life: important cognitive and neurological developments occur in this period. Mother's milk represents the primary source of nutrition in this period (Golding et al. 1997). Nevertheless, there are few studies approaching maternal smoking during lactation. Zanardo et al. (2005) showed that maternal smoking decreased proinflammatory cytokine IL $1 \alpha$ in breast milk. In an experimental model of maternal nicotine exposure during lactation, our group evidenced higher milk lactose levels and energy content (Oliveira et al. 2010). These previous findings suggest that smoke or its isolate components can alter breast milk and influence nutritional and immunologic status in pups. Nicotine-treated lactating dams presented hyperprolactinemia at the end of nicotine exposure, associated with lower food intake and hyperleptinemia (Oliveira et al. 2010). This was 
associated with some alterations in lipid profile of mothers and pups, such as higher high-density lipoprotein cholesterol (HDL-C). At weaning, offspring whose mothers were exposed to nicotine had type 2 diabetes (Bruin et al. 2007) and increased adipose tissue weight (Soom et al. 2008). When maternal nicotine exposure occurred only during lactation, the 15-day-old pups showed higher adiposity, hyperleptinemia, hypothyroidism, hypercorticosteronemia, and higher adrenal catecholamine content (Oliveira et al. 2009, 2010, Santos-Silva et al. 2010).

Smoking mothers are exposed to thousands of components that are present in tobacco smoke. Despite the fact that there have been an increasing number of animal studies on the basic neurobiology of nicotine exposure during development, tobacco compounds other than nicotine are likely to have their own effects or to have combined effects, including interactions with nicotine, resulting in altered nutritional and hormonal profiles of the offspring. Some compounds of cigarette smoke such as perchlorate and thiocyanate are excreted in urine and milk of breastfeeding women (Steinmaus et al. 2007). Breastfeeding infants from smoking mothers presented high urinary cotinine levels (Becker et al. 1999), confirming previous studies that showed that nicotine is transferred through the breast milk (Luck \& Nau 1987). Since nicotine alone has several effects during lactation both in mothers and in pups, we hypothesized that cigarette smoke as a whole may have the same or even more deleterious effects on maternal and pup physiology. The present study was thus designed to determine the effects of active smoking on maternal metabolism and the short-term endocrine and metabolic consequences for offspring passively exposed via milk, using an experimental model of postnatal cigarette smoke exposure.

\section{Materials and Methods}

Wistar rats were kept in a room with controlled temperature $\left(25 \pm 1^{\circ} \mathrm{C}\right)$ and with artificial darkness-light cycles (lights on from 0700 to $1900 \mathrm{~h}$ ). Three-month-old, virgin female rats were caged with male rats at a proportion of $2: 1$. After mating, each female was placed in an individual cage with free access to water and food until delivery. The use of animals was approved by the Animal Care and Use Committee of the Biology Institute of the State University of Rio de Janeiro (CEUA/016/2009) which based its analysis on the principles adopted and promulgated by Brazilian Law 11.794/2008, concerning the rearing and use of animals in teaching and research activities in Brazil (Marques et al. 2009).

\section{Model of maternal exposure to cigarette smoke during lactation}

Three days after birth, 16 lactating rats were randomly assigned to either the smoke (S) or control (C) group until 21 days of lactation. In the $\mathrm{S}$ group, dams $(n=8)$ were separated from pups and placed into a smoking chamber, $4 \times 1 \mathrm{~h}$ per day throughout the lactation period. This chamber received the smoke generated from an automatic cigarette-smoking machine (Model TE-10, Teague Enterprises, Davis, CA, USA) that burned one research cigarette type $2 \mathrm{R} 1 \mathrm{~F}$ at a time $(1.7 \mathrm{mg}$ nicotine/cigarette; Tobacco Research Institute, University of Kentucky, Lexington, KY, USA). A smoke mixture containing 89\% sidestream smoke (smoke released from the burning end of a cigarette) and 11\% mainstream smoke (smoke inhaled by an active smoker) as a surrogate for active smoking (Slotkin et al. 2001, Abreu-Villaça et al. 2010) was generated by the smoking machine in a staggered manner at the rate of a single $35 \mathrm{ml}$ puff of $2 \mathrm{~s}$ duration each min. During exposure, the total suspended particulate was measured by weighing teflon-coated fiber filters (TX40H120-WW, Pallflex Products Co., Putnam, CT, USA) before and after a 5 min period, when air was collected from the chamber. There were 12 periods of collection, of which each generated levels of $38.4 \pm 3.9 \mathrm{mg} / \mathrm{m}^{3}$ (mean \pm s.E.M.). In the $\mathrm{C}$ group, dams $(n=8)$ were separated from pups and placed into the chamber as described for the experimental group but exposed to filtered air.

At birth, litter adjustment was performed, with six male pups kept per $\mathrm{S}$ or $\mathrm{C}$ dam to maximize lactation performance. While dams were kept inside the chamber, pups were kept in their cages in a room with controlled temperature. At weaning (21 days of lactation), dams and pups were killed by rapid decapitation with no prior anesthesia because anesthesia affects hormone and lipid metabolism. We used two offspring from each mother (S pup, $n=16$ and C pup, $n=16$ ). Blood samples were collected and frozen at $-20{ }^{\circ} \mathrm{C}$ for further analysis.

\section{Nutritional evaluation}

During lactation, mother's body weight (BW) and food intake were daily monitored as well as pup's BW. Body length of the pups was measured every 3 days.

\section{Milk collection}

Milk samples were collected at 21 days of lactation. For this, mothers were separated from litters for $2 \mathrm{~h}$ before milking (Bonomo et al. 2005). After i.p. injection of oxytocin (5 UI/ml s.c. - Eurofarm, São Paulo, SP, Brazil) under pentobarbital anesthesia $(30 \mathrm{mg} / \mathrm{kg} \mathrm{BW})$, milk was manually collected from all teats. We obtained $0.5-1 \cdot 0 \mathrm{ml}$ from each lactating rat, and samples were frozen at $-20{ }^{\circ} \mathrm{C}$ for further analysis.

\section{Milk biochemistry analysis}

Total milk protein was measured according to the Peterson method (1977), with BSA as a standard. Protein concentration was determined based on the Stauffer formula (1975), and results were expressed in $\mathrm{mg} / \mathrm{ml}$. Total lipids were measured in milk samples diluted in distilled water $(1: 25)$ by colorimetric assay using a Bioclin commercial kit, and results 
were expressed in $\mathrm{mg} / \mathrm{dl}$. Milk lactose was measured by a colorimetric method using picric acid (Khramov et al. 2008), using commercial lactose as a standard (Sigma), and results were expressed in $\mathrm{mg} / \mathrm{ml}$. Milk energy was estimated using caloric value of each macronutrient (carbohydrate, lipids, and protein), and expressed in $\mathrm{kcal} / \mathrm{ml}$.

\section{Body composition evaluation}

Visceral fat mass (VFM) was excised and weighed for evaluation of the central adiposity - mesenteric, epididymal, and retroperitoneal (Toste et al. 2006). The carcasses of $\mathrm{C}$ and $\mathrm{S}$ pups were weighed, autoclaved for $1 \mathrm{~h}$, and homogenized on distilled water (1:1). Homogenate was stored at $4{ }^{\circ} \mathrm{C}$ for analysis (Fagundes et al. 2007). Three grams of homogenate were used to determine fat content gravimetrically. Samples were hydrolyzed on a shaking water bath at $70{ }^{\circ} \mathrm{C}$ for $2 \mathrm{~h}$ with $30 \% \mathrm{KOH}$ and ethanol. Total fatty acids and free cholesterol were removed with three successive washing with petroleum ether. After drying overnight in vacuum, tubes were weighed, and data were expressed as grams of fat by $100 \mathrm{~g}$ of carcass. One gram of homogenate was used for protein content determination by Lowry method (Lowry et al. 1951). Data were expressed as grams of protein per $100 \mathrm{~g}$ of carcass. The estimate of the subcutaneous fat was calculated by subtracting the visceral fat from the total fat.

\section{Morphological evaluation of maternal lung}

Samples of the right lung from $\mathrm{S}$ and $\mathrm{C}$ mothers were fixed in $4 \%$ paraformaldehyde for $72 \mathrm{~h}$; after that, all tissues were dehydrated, cleared, and then paraffin-embedded. Five micrometer-thick sections at the same level were obtained and stained with hematoxylin/eosin to assess morphology. To obtain uniform and proportional lung samples, 16 fields of each slide were observed at a magnification of $200 \times$, using a video microscope (Olympus BX40 linked to an Optronics CCD video camera system; Olympus, Center Valley, PA, USA). All evaluations were carried out by experimenters who did not know the group of dam or pup from which they received lung samples (numbered 1-32).

\section{Detection of cotinine (nicotine metabolite)}

Serum and milk cotinine levels were determined using a kit from Orasure Technologies (Bethlehem, PA, USA). At weaning, dams were separated from their litters and, $2 \mathrm{~h}$ later, milk was collected and stored at $-20^{\circ} \mathrm{C}$ until assayed (Bonomo et al. 2005). After that, $\mathrm{S}$ and $\mathrm{C}$ dams and pups were killed, and blood was collected. Blood was centrifuged (2000 $\mathrm{g}$, $20 \mathrm{~min})$, and supernatant was stored $\left(-20^{\circ} \mathrm{C}\right)$ until assaying.

\section{Serum biochemical parameters}

Glycemia was determined in the blood sample from the tail vein of fasting rats using a glucosimeter (ACCU-CHEK Advantage, Roche Diagnostics).
Total cholesterol (TC), triglycerides, and HDL-C were analyzed using Biosystem commercial test kits with an automated A15 spectrophotometer (Biosystems S.A., Barcelona, Spain). Low-density lipoprotein cholesterol (LDL-C) and very low-density lipoprotein cholesterol (VLDL-C) were calculated according to the Friedewald equation (Friedewald \& Levy 1972):

VLDL-C $=$ triglycerides $/ 5$

LDL-C $=(\mathrm{TC}-\mathrm{HDL}-\mathrm{C}-$ triglycerides $) / 5$.

\section{Serum hormone quantification by RIA}

Blood samples were centrifuged $\left(1500 \mathrm{~g} / 20 \mathrm{~min}\right.$ per $\left.4{ }^{\circ} \mathrm{C}\right)$ to obtain sera, which were kept at $-20{ }^{\circ} \mathrm{C}$ until the assay. All measurements were performed in one assay. Insulin was determined by commercial RIA kit (ImmuChem TM 125 I, coated tube, ICN Biomedicals, Inc., Orangeburg, NY, USA). Assay sensitivity was $1 \mu \mathrm{Ul} / \mathrm{ml}$, and intra-assay variation was $8.9 \%$. Leptin was measured by a specific RIA kit (Linco Research, Inc., St Louis, MO, USA) that measures both rat and mouse leptin (range of detection, $0.5-50 \mathrm{ng} / \mathrm{ml}$; intraassay variation, $2 \cdot 9 \%$ ). Adiponectin was determined by a commercial RIA kit (Millipore MADP, Billerica, MA, USA), with an assay sensitivity of $1 \mathrm{ng} / \mathrm{ml}$ and intra-assay variation of $3 \cdot 7 \%$. Total corticosterone was measured using a commercial RIA kit (ICN Biomedicals, Inc., Aurora, OH, USA) with an assay sensitivity of $50 \mathrm{ng} / \mathrm{ml}$ and an intra assay
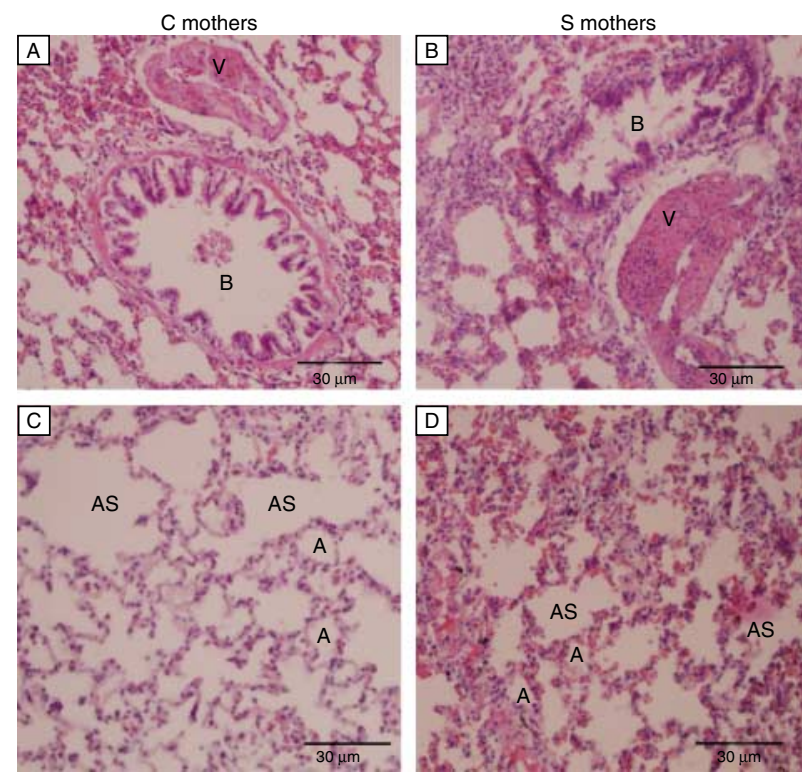

Figure 1 Photomicrographs of lung from tobacco smoke-exposed mothers during lactation ( $B$ and $D)$. Tissue sections were stained with hematoxylin-eosin. (A and C) Control mothers. B, bronchioles; $\mathrm{V}$, vessel; A, alveolus; and AS, airspace. $n=8$ dams per group. Full colour version of this figure available via http://dx.doi.org/10.1530/ JOE-10-0410. 
variation coefficient of 7\%. Prolactin (PRL) was determined by specific RIA using reagents supplied by the National Institute of Health (Maryland, MD, USA). Data were reported in $\mathrm{ng} / \mathrm{ml}$ from the reference preparation RP-3 with an assay sensitivity of $0.3 \mathrm{ng} / \mathrm{ml}$ and an intra-assay coefficient of $7 \cdot 5 \%$. Total triiodothyronine $\left(\mathrm{TT}_{3}\right)$ and free thyroxine $\left(\mathrm{FT}_{4}\right)$ were measured by RIA (ICN Pharmaceuticals, Inc., Los Angeles, CA, USA). Sensitivity limits were $25 \mathrm{ng} / \mathrm{dl}$ for $\mathrm{TT}_{3}$ and $0.3 \mathrm{ng} / \mathrm{dl}$ for $\mathrm{FT}_{4}$, and intra-assay variations were 3.5 and $6.5 \%$ respectively.

\section{Insulin sensitivity evaluation}

Insulin sensitivity was analyzed according to two formulae (Matthews et al. 1985):

The homeostasis model assessment of insulin resistance (HOMA-IR): (Insulin $(\mu \mathrm{IU} / \mathrm{ml}) \times$ serum glucose $(\mathrm{mmol} / \mathrm{l})) / 22 \cdot 5$; HOMA- $\beta$ : $(\operatorname{Insulin}(\mu \mathrm{IU} / \mathrm{ml}) \times 20) /$ serum glucose $(\mathrm{mmol} / \mathrm{l})-3 \cdot 5$.
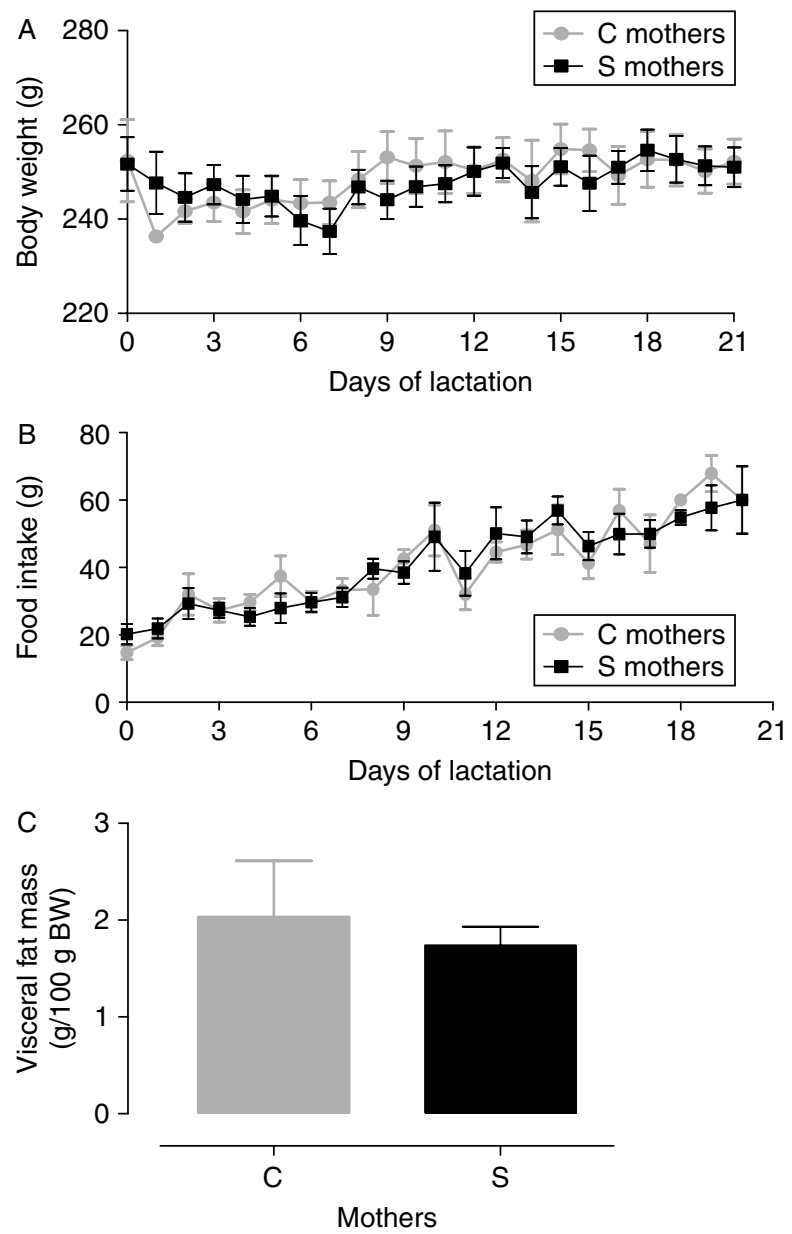

Figure 2 Body weight (A) and food intake (B) evolutions and visceral fat mass at weaning from tobacco smoke-exposed mothers during lactation (black) or control mothers (gray). Values represent mean and S.E.M. of eight dams per group.

Table 1 Glucose homeostasis and hormonal profile of tobacco smoke-exposed mothers during lactation. Values represent mean \pm s.E.M. of eight lactating rats per group

Glycemia (mg/dl)

Serum insulin $(\mu \mathrm{Ul} / \mathrm{ml})$

HOMA-IR

HOMA- $\beta$

Serum leptin (ng/ml)

Serum adiponectin $(\mathrm{ng} / \mathrm{ml})$

Serum PRL (ng/ml)

Adrenal catecholamine content $(\mu \mathrm{M} / \mathrm{g})$

Serum corticosterone $(\mathrm{ng} / \mathrm{ml})$

Serum $\mathrm{TT}_{3}(\mathrm{ng} / \mathrm{dl})$

Serum $\mathrm{FT}_{4}(\mathrm{ng} / \mathrm{dl})$

$\begin{array}{ccc}\text { Control group } & & \text { Smoke group } \\ 77 \cdot 0 \pm 5 \cdot 6 & & 69 \cdot 3 \pm 3 \cdot 9 \\ 43 \cdot 7 \pm 3 \cdot 9 & & 26 \cdot 6 \pm 3 \cdot 5^{*} \\ 9 \cdot 4 \pm 1 \cdot 2 & & 4 \cdot 4 \pm 0 \cdot 8^{*} \\ 234 \cdot 3 \pm 32 \cdot 2 & & 160 \cdot 0 \pm 29 \cdot 4 \\ 1 \cdot 6 \pm 0 \cdot 2 & & 0 \cdot 9 \pm 0 \cdot 1^{*} \\ 2 \cdot 0 \pm 0 \cdot 2 & & 1 \cdot 9 \pm 0 \cdot 2 \\ 3 \cdot 9 \pm 0 \cdot 6 & & 7 \cdot 8 \pm 1 \cdot 5^{*} \\ 0 \cdot 40 \pm 0 \cdot 23 & & 0 \cdot 69 \pm 0 \cdot 21 \\ & & \\ 364 \cdot 0 \pm 61 \cdot 2 & & 255 \cdot 3 \pm 59 \cdot 5 \\ 48 \cdot 7 \pm 4 \cdot 5 & & 45 \cdot 3 \pm 3 \cdot 1 \\ 0 \cdot 51 \pm 0 \cdot 11 & & 0 \cdot 50 \pm 0 \cdot 09\end{array}$

*Significant differences between groups $(P<0 \cdot 05)$.

\section{Adrenal catecholamine content measurement}

For catecholamine content, left adrenal glands were homogenized in $500 \mu \mathrm{l}$ of $10 \%$ acetic acid and centrifuged (10 $000 \boldsymbol{g}$ for $1 \mathrm{~min}$ ). To assay, $50 \mu \mathrm{l}$ of supernatant/epinephrine standards were mixed with $250 \mu \mathrm{l}$ of buffer phosphate $0.5 \mathrm{M}, \mathrm{pH} 7 \cdot 0$ and $25 \mu \mathrm{l}$ of potassium ferricyanate $0 \cdot 5 \%$, followed by incubation (20 min; ice bath). Reaction was stopped with $500 \mu \mathrm{l}$ of ascorbic acid/ $\mathrm{NaOH} 10 \mathrm{M}$ (1:19 proportion). Parameters used in the fluorometer (Victor2, PerkinElmer, Waltham, MA, USA) were $420 \mathrm{~nm}$ excitation and $510 \mathrm{~nm}$ emission. Results were obtained by plotting the values into a linear regression of the standard epinephrine curve. Data were expressed by $\mu \mathrm{M}$ catecholamines/mg gland (Trevenzoli et al. 2007).

\section{Statistical analysis}

Results were reported as mean \pm s.E.M. GraphPad Prism 5 was used for statistical analyses and graphics (GraphPad Software, Inc., La Jolla, CA, USA). Changes in BW and food intake were analyzed by two-way ANOVA and Newman-Keuls multiple comparison tests. The other experimental data were analyzed by unpaired Student's $t$-test with significance level set at $P<0 \cdot 05$. We studied two offspring from each mother (16 pups per group). However, for the analyses, litter was used as the experimental unit so that we considered the average of values from animals of the same litter instead of using individual animal values.

\section{Results}

Tobacco smoke exposure affected cotinine milk and serum levels. In $\mathrm{S}$ dams, milk and serum cotinine concentrations were similar (milk, 107.6 $\pm 6.6 \mathrm{ng} / \mathrm{ml}$; serum, 105.1 $\pm 9 \cdot 6 \mathrm{ng} / \mathrm{ml})$. S pups at 21 days old had serum cotinine levels of $17.9 \pm 4.2 \mathrm{ng} / \mathrm{ml}$. Control dams and pups had cotinine levels below the detection limit of the technique $(<8 \mathrm{ng} / \mathrm{ml})$. 
Table 2 Lipid profile of tobacco smoke-exposed mothers during lactation. Values represent mean \pm S.E.M. of eight lactating rats per group

\begin{tabular}{lrcc} 
& Control group & & Smoke group \\
\cline { 2 - 2 } Total cholesterol $(\mathrm{mg} / \mathrm{dl})$ & $70 \cdot 4 \pm 3 \cdot 6$ & & $67 \cdot 6 \pm 4 \cdot 5$ \\
Triglycerides $(\mathrm{mg} / \mathrm{dl})$ & $116 \cdot 3 \pm 5 \cdot 7$ & & $55 \cdot 4 \pm 5 \cdot 8^{*}$ \\
HDL-C $(\mathrm{mg} / \mathrm{dl})$ & $51 \cdot 4 \pm 2 \cdot 0$ & & $52 \cdot 4 \pm 2 \cdot 4$ \\
LDL-C $(\mathrm{mg} / \mathrm{dl})$ & $8 \cdot 0 \pm 0 \cdot 9$ & & $7 \cdot 3 \pm 1 \cdot 3$ \\
VLDL-C $(\mathrm{mg} / \mathrm{dl})$ & $23 \cdot 3 \pm 1 \cdot 1$ & & $11 \cdot 1 \pm 1 \cdot 2^{*}$
\end{tabular}

*Significant differences between groups $(P<0 \cdot 05)$.

The pulmonary morphology (Fig. 1) showed histological abnormalities (as goblet cell depletion) in mothers who were exposed to cigarette smoke, such as alteration of bronchiolar structure, blood vessel, and alveolus. The bronchioles showed alteration in the epithelium as well as an increase of vessel thickness with hypertrophy, where tunica adventitia and media were not differentiated. Alveolus showed septa destruction with disruption and decrease of functional airspace, inflammation with macrophages, and neutrophils.

At weaning, $\mathrm{S}$ dams exhibited no change in BW, food intake, and VFM compared to control group as observed in Fig. 2. Hormonal profile is shown in Table 1. At the end of lactation, S dams presented hypoinsulinemia $(-40 \%$, $P<0 \cdot 05)$, hypoleptinemia $(-46 \%, P<0 \cdot 05)$, and hyperprolactinemia $(+50 \%, P<0 \cdot 05)$, while glycemia, adiponectinemia, serum thyroid hormones, corticosteronemia, and adrenal catecholamine were unchanged. Concerning insulin sensitivity (Table 1), S dams presented lower HOMA-IR $(-53 \%$ versus $\mathrm{C}, P<0 \cdot 05)$ but no significant change of HOMA- $\beta$. As shown in Table 2, $\mathrm{S}$ dams showed lower serum triglycerides $(-53 \%, P<0 \cdot 05)$ and VLDL-C $(-50 \%$, $P<0 \cdot 05)$, while cholesterol evaluations were normal. In milk (Table 3), tobacco smoke exposure caused higher lactose, triglycerides content $(+52$ and $+78 \%, P<0.05$ respectively), and calories $(+19 \%)$, while protein, cholesterol, and total lipids were normal.

Pups whose mothers were smoke-exposed during lactation were comparable to control pups concerning BW gain and body length (Fig. 3). Concerning body composition evaluation (Fig. 4), S pups showed lower total and subcutaneous fat $(-24 \%$ Fig. $4 \mathrm{~B}$ and $-25 \%$ Fig. 4C, $P<0.05$ respectively) and no alteration of the VFM with higher body protein content (Fig. 4D, $+17 \%, P<0 \cdot 05$ ). Hormone levels of pups whose mothers were smoke-exposed during lactation are depicted in Table 4 . Weaned $\mathrm{S}$ pups showed higher insulinemia $(+28 \%, P<0 \cdot 05)$, lower glycemia $(-11 \%, P<0 \cdot 05)$, lower corticosteronemia $(-40 \%$, $P<0 \cdot 05)$, and lower adrenal catecholamine content $(-40 \%$, $P<0 \cdot 05)$ compared to C pups; however, adiponectin, PRL, and thyroid hormone levels were unchanged. This group also showed higher HOMA- $\beta(+47 \%, P<0 \cdot 05$, Table 4$)$. The lipid profile of $\mathrm{S}$ pups is described in Table 5. At 21 days old,

$\mathrm{S}$ pups presented higher serum triglycerides $(+34 \%$, $P<0 \cdot 05)$, lower LDL-C, and higher HDL-C levels $(-45$ and $+16 \%, P<0 \cdot 05$ respectively).

\section{Discussion}

There are a large number of compounds found in tobacco smoke, at least 4000 bioactive compounds were already reported, most of them with toxicological effects such as nicotine, formaldehyde, cadmium, and urethane (Balharry et al. 2008). Our data using cigarettes with a high nicotine dose $(1.7 \mathrm{mg} /$ cigarette; the main addictive compound of cigarettes) showed similar cotinine concentrations in serum and milk. This fact confirms the transfer of nicotine to the milk and shows the effectiveness of our model of passive exposure of offspring to smoke. The short half-life of cotinine $(5 \cdot 2 \mathrm{~h})$ in rats (Kyerematen \& Vesell 1991) and the interval between the last exposure of mothers to smoke and the killing (2 h) explain the low cotinine levels of S pups. Thus, offspring were exposed to low nicotine levels and only through the milk, similar to what occurs with infants whose mothers smoked between the breastfeeding periods, away from their babies.

We showed pathological changes in the lung of $\mathrm{S}$ dams, which were also found in other models of tobacco smoke exposure (Chen et al. 2008, Zhang et al. 2008a,b). Dams of $\mathrm{S}$ group presented alterations in bronchioles, vessels, and alveoli. These alterations lead to an alveolar disturbance, cellular hyperplasia, and inflammatory infiltration. Clearly, this suggests that smoke has potent inflammatory agents that activate inflammatory proteins such as cytokines, growth factors, and adhesion molecules, which causes changes in lung function and structure. It is known that quinones and hydroquinones detected in tobacco smoke are responsible for the generation of reactive oxygen species (Hecht 1999, Yu et al. 2002). This oxidative stress may cause a local inflammatory response, with higher IL12, tumour necrosis factor- $\alpha$, neutrophils, macrophages and lymphocytes that may be related to the morphological changes observed (Zheng et al. 2009, Braber et al. 2010). Taken together, the morphological changes of maternal lung and high cotinine levels in serum and milk confirm the effectiveness of smoke

Table 3 Milk biochemical composition of tobacco smoke-exposed mothers during lactation. Values represent mean \pm S.E.M. of eight lactating rats per group

Lactose $(\mathrm{mg} / \mathrm{ml})$

Protein $(\mathrm{mg} / \mathrm{ml})$

Cholesterol $(\mathrm{mg} / \mathrm{dl})$

Triglycerides (mg/dl)

Total lipids $(\mathrm{ng} / \mathrm{ml})$

Calories $(\mathrm{kcal} / \mathrm{ml})$

\begin{tabular}{ccc} 
Control group & & Smoke group \\
$24 \cdot 4 \pm 3 \cdot 1$ & & $37 \cdot 2 \pm 3 \cdot 1^{*}$ \\
$109 \cdot 7 \pm 18 \cdot 4$ & & $96 \cdot 9 \pm 7 \cdot 5$ \\
$530 \cdot 3 \pm 54 \cdot 7$ & & $530 \cdot 6 \pm 31 \cdot 3$ \\
$18140 \pm 3155$ & & $32320 \pm 2474^{*}$ \\
$3717 \pm 861$ & & $4125 \pm 581$ \\
$26 \cdot 0 \pm 3 \cdot 7$ & & $31 \cdot 0 \pm 4 \cdot 7^{*}$ \\
\hline
\end{tabular}

*Significant differences between groups $(P<0 \cdot 05)$. 

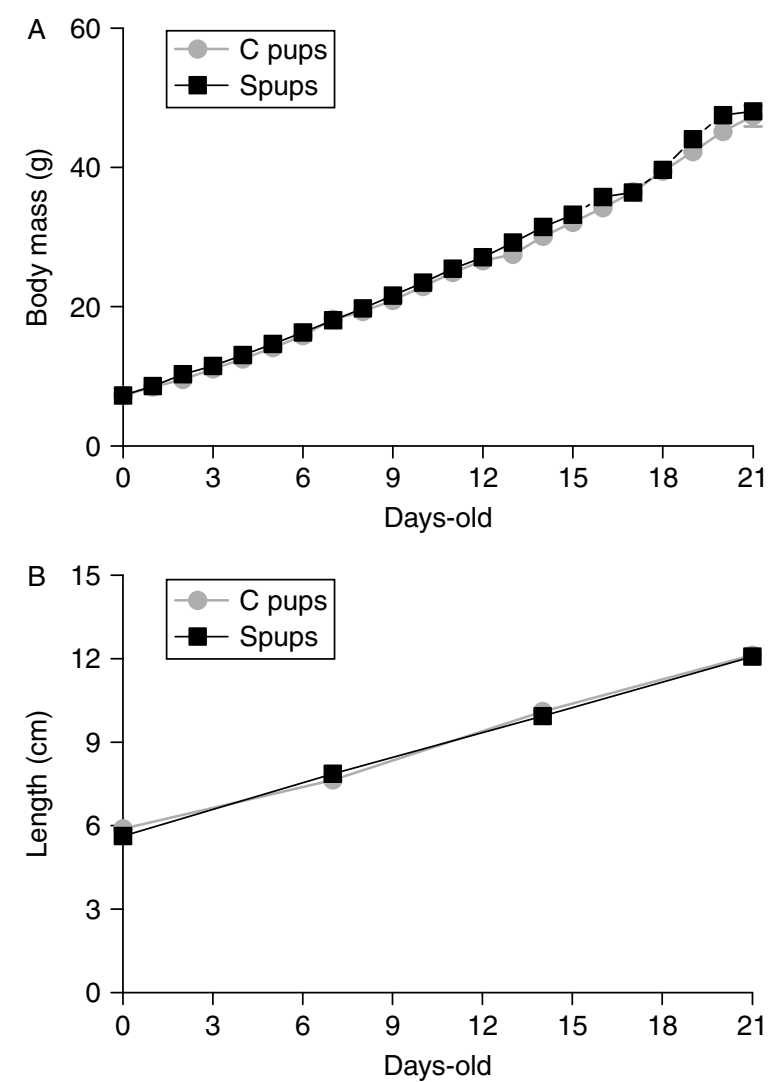

Figure 3 Body weight (A) and body length (B) of pups whose mothers were tobacco smoke-exposed (black) or not (gray) during lactation. Values represent mean and S.E.M. of eight pups per group.

exposure in our experimental model of active maternal smoking during lactation.

Despite the data showing the reduction of BW and food intake in animals under tobacco smoke or nicotine exposure (Arai et al. 2001, Chen et al. 2005, 2006, 2008), we observed that $\mathrm{S}$ dams did not present changes of these parameters throughout the lactation period. A simplistic explanation for this fact could be the relatively short period of smoke exposure (18 days of lactation). However, this short period was already enough to produce important lung morphological changes. Further, we cannot discard the importance of maternal hormonal changes observed in the present study, such as hypoleptinemia and hyperprolactinemia, also observed by Oliveira et al. (2010) in nicotine-treated mothers during lactation, to produce a counterbalance of nicotine effects upon BW and food intake control. Leptin is an anorexigenic hormone produced by adipocytes (Ahima et al. 1996), and PRL, which allows the initiation and maintenance of breastfeeding (Hill et al. 1999), is responsible for maternal hyperphagia during this period (Grattan 2001). Thus, lower leptin and higher PRL could avoid the anorexigenic effect of smoking, promoting the unchanged food intake and BW of dams, perhaps in order to ensure the maintenance of energy homeostasis in this critical period.
Regarding glucose homeostasis, $\mathrm{S}$ mothers showed normoglycemia and hypoinsulinemia. Normoglycemia was described in rats exposed to tobacco smoke during pregnancy (Sinzato et al. 2008) associated with lower liver glycogen content and glucose intolerance. In addition, some studies have associated smoking in adult humans with the development of insulin resistance (Chiolero et al. 2008). In contrast, in the present study, S mothers presented lower HOMA-IR suggesting higher insulin sensitivity. This hypoinsulinemia can be due to lower insulin secretion from pancreatic $\beta$ cells that in a long term could lead to the development of glycemic intolerance. It is known that PRL stimulates and leptin inhibits insulin secretion in pancreatic $\beta$ cells (Arumugan et al. 2010, Park et al. 2010). However, both hypoleptinemia and hyperprolactinemia of $\mathrm{S}$ mothers were not sufficient to maintain insulin levels. Thus, the physiological period of life, especially lactation, or the duration of smoke exposure can determine whether the organism will be more sensitive or resistant to insulin in response to smoking.

Smoking affects the thyroid gland (Christensen et al. 1984, Fisher et al. 1997, Utiger 1998), and thiocyanate is associated with hypothyroidism (Fukayama et al. 1992, Muller et al. 1995). During lactation, smoking mothers transfer less iodine through milk (Lauberg et al. 2004). In our study, S dams did not show serum thyroid hormone alterations. Probably, the short-term smoke exposure was not enough for changing the maternal thyroid function.

Milk from $\mathrm{S}$ mothers presented high triglycerides and lactose levels that contribute to an offer of a hypercaloric milk to pups. Lower triglyceridemia of $\mathrm{S}$ mothers can be due to a higher transfer of this macronutrient to the pups through the milk and confirms previous studies ( $\mathrm{Ng}$ et al. 2009). Among cigarette substances, nicotine can be responsible for this change because a similar effect was found in the model of maternal nicotine exposure during lactation (Oliveira et al. 2010). Accordingly, these biochemical
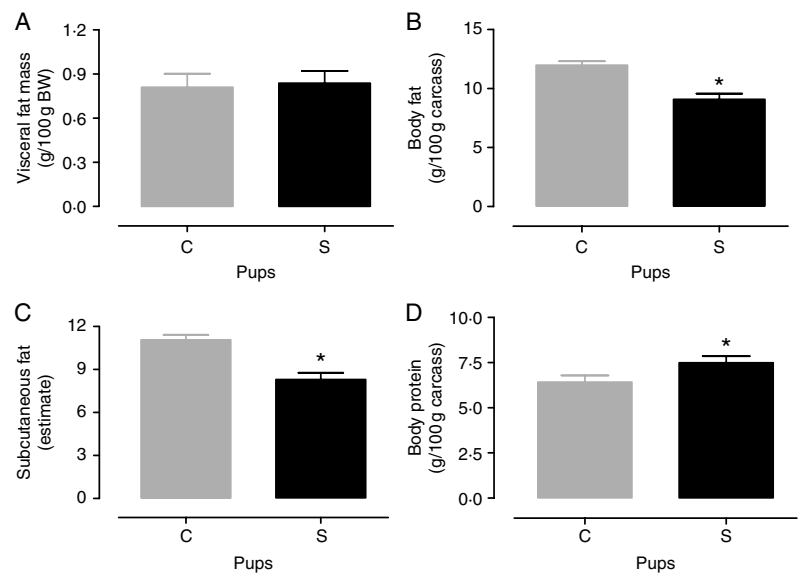

Figure 4 Visceral fat mass (A), body fat (B), subcutaneous fat (C), and body total protein (D) of pups whose mothers were tobacco smoke-exposed (black) or not (gray) during lactation. Values represent mean and S.E.M. of eight pups per group. ${ }^{*} P<0 \cdot 05$. 
Table 4 Glucose homeostasis and hormonal profile of pups whose mothers were tobacco smoke-exposed during lactation. Values represent mean \pm S.E.M. of eight pups per group

\begin{tabular}{|c|c|c|}
\hline & Control group & Smoke group \\
\hline Glycemia (mg/dl) & $109 \cdot 8 \pm 2 \cdot 5$ & $98 \cdot 2 \pm 2 \cdot 4^{*}$ \\
\hline Serum insulin $(\mu \mathrm{Ul} / \mathrm{ml})$ & $27 \cdot 5 \pm 2 \cdot 9$ & $35 \cdot 1 \pm 2 \cdot 6^{*}$ \\
\hline HOMA-IR & $7 \cdot 1 \pm 0 \cdot 8$ & $9 \cdot 0 \pm 1 \cdot 2$ \\
\hline HOMA- $\beta$ & $82 \cdot 1 \pm 7 \cdot 4$ & $121 \cdot 2 \pm 12 \cdot 5^{*}$ \\
\hline Serum leptin (ng/ml) & $2 \cdot 0 \pm 0 \cdot 3$ & $2 \cdot 4 \pm 0 \cdot 3$ \\
\hline Serum adiponectin (ng/ml) & $1 \cdot 3 \pm 0 \cdot 1$ & $1 \cdot 4 \pm 0 \cdot 1$ \\
\hline Serum PRL (ng/ml) & $4 \cdot 43 \pm 0 \cdot 85$ & $4 \cdot 45 \pm 1 \cdot 05$ \\
\hline $\begin{array}{l}\text { Adrenal catecholamine } \\
\text { content }(\mu \mathrm{M} / \mathrm{g})\end{array}$ & $0 \cdot 53 \pm 0 \cdot 07$ & $0 \cdot 32 \pm 0 \cdot 05^{*}$ \\
\hline Serum corticosterone (ng/ml) & $155 \cdot 7 \pm 27 \cdot 0$ & $94 \cdot 5 \pm 13 \cdot 4^{*}$ \\
\hline Serum $\mathrm{TT}_{3}(\mathrm{ng} / \mathrm{dl})$ & $148 \cdot 6 \pm 5 \cdot 9$ & $146 \cdot 4 \pm 4 \cdot 8$ \\
\hline Serum $\mathrm{FT}_{4}(\mathrm{ng} / \mathrm{dl})$ & $0.92 \pm 0.09$ & $0 \cdot 91 \pm 0 \cdot 12$ \\
\hline
\end{tabular}

*Significant differences between groups $(P<0 \cdot 05)$.

alterations in milk can be a protective mechanism, providing more energy to the pups. In accordance with this suggestion, previous studies show that smoke exposure is associated with reduced oxygen partial pressure in dams signaling a deficient nutritional offer to the mother.

Smoke in pregnancy is related to being overweight in childhood (Von Kries et al. 2002, Wideroe et al. 2003), and higher total body fat mass was described in suckling pups whose mothers were nicotine-treated during lactation (Oliveira et al. 2009). However, in the present model, S pups showed no change in $\mathrm{BW}$ at weaning, despite higher body protein and lower body fat mass. Higher body protein can be due to hyperinsulinemia of S pups that can increase amino acids uptake in the muscle. Since visceral adiposity was not altered in S pups, lower body fat was caused exclusively by lower subcutaneous fat content. Although the subcutaneous adipocyte is the main site of leptin production, its reduction did not affect serum leptin levels in S pups. This kind of dissociation between fat mass and leptinemia was already reported in other models (Toste et al. 2006, Rodrigues et al. 2009). Although we cannot draw a direct comparison between the models of nicotine exposure and ETS exposure, Oliveira et al. (2009) observed higher adiposity and hyperleptinemia in pups from nicotine-treated dams on lactation, while in the present study, we found lower body fat in S pups, which can be associated with other cigarette components or substances conveyed through the milk, since $\mathrm{S}$ offspring had no direct contact with cigarette smoke.

Concerning the lipid profile of S pups, we detected higher serum triglycerides, resulting from the higher transfer through maternal milk. Hypertriglyceridemia can still be indicative of fatty liver development that is related to smoking (Chiang et al. 2009, Mallat \& Lotersztajn 2010). Tobacco smoke is related to decreased Apo AI and other cardiometabolic alterations in children exposed to ETS (Nagel et al. 2009); however, in our model, $\mathrm{S}$ pups had higher HDL-C levels suggesting an adaptive defense mechanism against tobacco smoke effects. Perhaps, nicotine is responsible for higher serum HDL-C because recently we evidenced this effect in suckling pups whose mothers were treated with nicotine during lactation (Oliveira et al. 2010). In addition, according to $\mathrm{Ng}$ et al. (2009), female pups whose mothers were exposed to tobacco in pregnancy showed higher HDL-C.

As already mentioned, smoking exposure and nicotine exposure are related to the development of insulin resistance and type 2 diabetes (Chiolero et al. 2008, Somm et al. 2009). Despite lower glycemia (only $11 \%$ less than controls) and no change of adiponectin level, $\mathrm{S}$ pups showed hyperinsulinemia and higher HOMA- $\beta$, suggesting a risk for the future development of insulin resistance.

Detection of lower serum corticosterone and adrenal catecholamine content in $\mathrm{S}$ offspring under basal conditions may be related to lower response to stress and suggest that some components of smoke have a direct inhibitory effect in the adrenal gland of the pups. On the contrary, exclusive exposure to nicotine (Oliveira et al. 2010) leads to higher corticosteronemia and adrenal catecholamine content in suckling pups. This fact shows that exposure to nicotine alone has opposite effects when associated with other cigarette components. Thus, other smoke substances may have contrary and more marked effects than nicotine over adrenal function. Since it is well known that catecholamine decreases insulin secretion, and both catecholamines and corticosterone are hyperglycemic hormones, the lower levels of these two hormones of $\mathrm{S}$ offspring could help to explain the hyperinsulinism combined with lower blood glucose levels.

Maternal smoking influences the thyroid function of the infants (Meberg \& Marstein 1986, Chanoine et al. 1991). In the present study, S pups did not display changes of thyroid hormone levels. Previously, we demonstrated that neonate pups from-nicotine treated dams presented primary hypothyroidism (Oliveira et al. 2009). It is interesting to note that in the two models, the serum levels of cotinine detected in the progeny, although low, are similar as well as the period of exposure. Thus, again there was a dissociation between the effects of isolated nicotine exposure and those of other smoke components.

Previously, we evidenced that maternal nicotine exposure during the lactation period leads to metabolic alterations in both dams and pups (Oliveira et al. 2009, 2010). In the present

Table 5 Lipid profile of pups whose mothers were tobacco smokeexposed during lactation. Values represent mean \pm S.E.M. of eight pups per group

\begin{tabular}{lccc} 
& Control group & & Smoke group \\
Total cholesterol $(\mathrm{mg} / \mathrm{dl})$ & $157 \cdot 3 \pm 10 \cdot 5$ & & $137 \cdot 7 \pm 5 \cdot 0$ \\
Triglyceride $(\mathrm{mg} / \mathrm{dl})$ & $155 \cdot 6 \pm 22 \cdot 9$ & & $208 \cdot 2 \pm 17 \cdot 0^{*}$ \\
HDL-C $(\mathrm{mg} / \mathrm{dl})$ & $58 \cdot 9 \pm 2 \cdot 0$ & & $68 \cdot 5 \pm 1 \cdot 7^{*}$ \\
LDL-C $(\mathrm{mg} / \mathrm{dl})$ & $68 \cdot 0 \pm 3 \cdot 2$ & & $37 \cdot 6 \pm 2 \cdot 9^{*}$ \\
VLDL-C $(\mathrm{mg} / \mathrm{dl})$ & $35 \cdot 2 \pm 5 \cdot 8$ & & $41 \cdot 6 \pm 3 \cdot 4$ \\
\cline { 2 - 3 } & & & \\
\hline
\end{tabular}

*Significant differences between groups $(P<0 \cdot 05)$. 
model of maternal exposure to smoke in postnatal life, we observed that some nutritional, hormonal, and metabolic alterations were similar (i.e. high milk lactose and maternal hyperprolactinemia), while others were different (i.e. hypothyroidism, adrenal hormonal changes, hyperleptinemia, and higher adiposity in suckling pups) when compared to maternal exposure to nicotine during lactation (Oliveira et al. 2009, 2010), which suggests different effects of nicotineisolated exposure when compared to effects elicited by tobacco smoke components. However, we must be careful in making direct comparisons between the two models, due to differences in the route of administration, time, and frequency of exposure, which hinders a clear interpretation. It is the first time that the effects of smoking exposure during lactation on this dataset were shown.

In conclusion, our model of maternal exposure to cigarette smoke exclusively during lactation highlights the deleterious effects on nutritional, biochemical, and hormonal profiles of both mothers and neonates. Therefore, the implication from these results is that women who are breastfeeding should avoid exposure to tobacco smoke, even in the absence of the child.

\section{Declaration of interest}

The authors declare that there is no conflict of interest that could be perceived as prejudicing the impartiality of the research reported.

\section{Funding}

This research was supported by the 'National Council for Scientific and Technological Development' (Conselho Nacional de Desenvolvimento Científico e Tecnológico - CNPq), the 'Carlos Chagas Filho Research Foundation of the State of Rio de Janeiro' (Fundação Carlos Chagas Filho de Amparo à Pesquisa do Estado do Rio de Janeiro - FAPERJ), and the Coordination for the Enhancement of Higher Education Personnel (Coordenação de Aperfeiçoamento de Pessoal de Nível Superior - CAPES). A P S S and C R P were recipients of a CNPq fellowship. A L N F and A C S were recipients of a FAPERJ fellowship. E $\mathrm{O}$ was recipient of a CAPES fellowship.

\section{Acknowledgements}

All authors are grateful to Ms Mônica Moura, Mr Ulisses Siqueira, and Mr Carlos Alberto Guimarães for their technical assistance.

\section{References}

Abreu-Villaça Y, Filgueiras CC, Guthierrez M, Medeiros AH, Mattos MA, Pereira Mdos S, Manhães AC \& Kubrusly RC 2010 Exposure to tobacco smoke containing either high or low levels of nicotine during adolescence: differential effects on choline uptake in the cerebral cortex and hippocampus. Nicotine and Tobacco Research 12 776-788. (doi:10.1093/ntr/ ntq075)

Ahima RS, Prabakaran D, Mantzoros C, Qu D, Lowell B, Maratos-Flier E \& Flier JS 1996 Role of leptin in the neuroendocrine response to fasting. Nature 382 250-252. (doi:10.1038/382250a0)
Arai K, Kim K, Kaneko K, Iketani M, Otagiri A, Yamauchi N \& Shibasaki T 2001 Nicotine infusion alters leptin and uncoupling protein 1 mRNA expression in adipose tissues of rats. American Journal of Physiology. Endocrinology and Metabolism 280 867-876.

Arumugan R, Horowitz E, Noland RC, Lu D, Fleenor D \& Freemark M 2010 Regulation of islet beta-cell pyruvate metabolism: interactions of prolactin, glucose, and dexemethasone. Endocrinology 151 3074-3083. (doi:10.1210/en.2010-0049)

Balharry D, Sexton K \& BéruBé KA 2008 An in vitro approach to assess the toxicity of inhaled tobacco smoke components: nicotine, cadmium, formaldehyde and urethane. Toxicology 244 66-76. (doi:10.1016/j.tox. 2007.11.001)

Becker AB, Manfreda J, Ferguson AC, Dimich-Ward H, Watson WT \& Chan-Yeung M 1999 Breast-feeding and environmental tobacco smoke exposure. Archives of Pediatrics and Adolescent Medicine 153 689-691.

Bonomo IT, Lisboa PC, Passos MC, Pazos-Moura CC, Reis AM \& Moura EG 2005 Prolactin inhibition in lactating rats changes leptin transfer through the milk. Hormone Metabolic Research 37 220-225. (doi:10.1055/ s-2005-861381)

Braber S, Henricks PAJ, Nijkamp FP, Kraneveld AD \& Folkerts G 2010 Imflammatory changes in the airways of mice causes by cigarettes smoke exposure are only partially reversed after smoking cessation. Respiratory Research 11 99-109. (doi:10.1186/1465-9921-11-99)

Bruin JE, Kellenberger LD, Gerstein HC, Mmorrison K \& Holloway AC 2007 Fetal and neonatal nicotine exposure and postnatal glucose: identifying critical windows of exposure. Journal of Endocrinology 194 171-178. (doi:10.1677/JOE-07-0050)

Chanoine JP, Toppet V, Bourdoux P, Spehl M \& Delange F 1991 Smoking during pregnancy: a significant cause of neonatal thyroid enlargement. British Journal of Obstetrics and Gynaecology 98 65-68. (doi:10.1111/ j.1471-0528.1991.tb10313.x)

Chen H, Vlahos R, Bozinovski S, Jones J, Andreson JP \& Morris MJ 2005 Effects of short-term cigarette smoke exposure on body weight, appetite and brain neuropeptide Y in mice. Neuropsychopharmacology 30 713-719. (doi:10.1038/sj.npp.1300597)

Chen H, Hansen MJ, Jones JE, Vlahos R, Bozinovcki S, Anderson GP \& Morrin MJ 2006 Cigarette smoke exposure reprograms the hypothalamic neuropeptide Y axis to promove weight loss. American Journal of Respiratory and Critical Care Medicine 173 1248-1254. (doi:10.1164/rccm.200506977OC)

Chen H, Hansen MJ, Jones JE, Vlahos R, Anderson GP \& Morris MJ 2008 Long-term cigarette smoke exposure increases protein expression but reduces energy intake. Brain Research 1228 81-88. (doi:10.1016/j.brainres. 2008.06.067)

Chiang PH, Chang TY \& Chen JD 2009 Synergistic effect of fatty liver and smoking on metabolic syndrome. World Journal of Gastroenterology 15 5334-5339. (doi:10.3748/wjg.15.5334)

Chiolero A, Faeh D, Paccaud F \& Cornuz J 2008 Consequences of smoking for body weight, body distribution and insulin resistance. American Journal of Clinical Nutrition 87 801-809.

Chou SY, Hsu HH, Kuo HH \& Kuo HW 2007 Association between exposure to environmental tobacco smoke (ETS) and breastfeeding behaviour. Acta Paediatrica 97 76-80. (doi:10.1111/j.1651-2227.2007.00593.x)

Christensen SB, Ericsson UB, Janzon L, Tibblin S \& Melander A 1984 Influence of cigarette smoking on goiter formation, thyroglobulin, and thyroid hormone levels in women. Journal of Clinical Endocrinology and Metabolism 58 615-618. (doi:10.1210/jcem-58-4-615)

Einarson A \& Riordan S 2009 Smoking in pregnancy and lactation: a review of risks and cessation strategies. European Journal of Clinical Pharmacology 65 325-330. (doi:10.1007/s00228-008-0609-0)

Fisher CL, Mannino DM, Herman WH \& Frumkin H 1997 Cigarette smoking and thyroid hormone levels in males. International Journal of Epidemiology 26 972-977. (doi:10.1093/ije/26.5.972)

Friedewald WT \& Levy RI 1972 Estimation of the concentration of low density lipoprotein cholesterol in plasma, without use of the preparative ultracentrifuge. Clinical Chemistry 18 499-502. 
Fukayama H, Nasu M, Murakami S \& Sugawara M 1992 Examination of antithyroid effects of smoking products in cultured thyroid follicles: only thiocyanate is a potent antithyroid agent. Acta Endocrinologica 127 520-525. (doi:10.1530/acta.0.1270520)

Grattan DR 2001 The action of prolactin in the brain during pregnancy and lactation. Progress in Brain Research 133 153-171.

Golding J, Rogers IS \& Emmett PM 1997 Association between breast feeding, child development and behaviour. Early Human Development 29 S175-S184. (doi:10.1016/S0378-3782(97)00062-5)

Hecht SS 1999 Tobacco smoke carcinogens and lung cancer. Journal of National Cancer Institute 91 1194-1210. (doi:10.1093/jnci/91.14.1194)

Hegaard HK, Kjaergaard H, Møller LF, Wachmann H \& Ottesen B 2006 The effects of environmental tobacco smoke during during pregnancy on birth weight. Acta Obstetricia et Gynecologica Scandinavica 85 675-681. (doi:10.1080/00016340600607032)

Hill PD, Chatterton RT \& Aldag JC 1999 Serum prolactin in breastfeeding: state of science. Biological Research for Nursing 1 65-75. (doi:10.1177/ 109980049900100109)

Khramov VA, Kolomeitseva AS \& Papichev NV 2008 Jaffe color test-based microtechnique for determination of milk lactose. Gigiena $i$ Sanitariia 3 86-87.

Kyerematen GA \& Vesell ES 1991 Metabolism of nicotine. Drug Metabolism Reviews 23 3-41. (doi:10.3109/03602539109029754)

Ladomenou F, Kafatos A \& Galanakis E 2009 Environmental tobacco smoke exposure as a risk factor for infections in infancy. Acta Paediatrica $\mathbf{9 8}$ 1137-1141. (doi:10.1111/j.1651-2227.2009.01276.x)

Lauberg P, NØHR SB, Pedersen KM \& Fuglsang EJ 2004 Iodine nutrition in breast-fed infants is impaired by maternal smoking. Journal of Clinical Endocrinology and Metabolism 89 181-187. (doi:10.1210/jc.2003-030829)

Lowry OH, Roseberough NJ, Farr AL \& Randal RJ 1951 Protein measurement with the folin phenol reagent. Journal of Biological Chemistry $193265-275$.

Luck W \& Nau H 1987 Nicotine and cotinine concentrations in the milk of smoking mothers: influence of cigarette consumption and diurnal variation. European Journal of Pediatrics 146 21-26. (doi:10.1007/BF00647276)

Mallat A \& Lotersztajn S 2009 Cigarette smoke exposure: A novel cofactor of NAFLD progression? Journal of Hepatology 51 430-432. (doi:10.1016/j. jhep.2009.05.021)

Mantzoros CS, Varvarigou A, Kaklamani VG, Beratis NG \& Flier JS 1997 Effect of birth weight and maternal smoking on cord blood leptin concentrations of full-term and preterm newborns. Clinics in Endocrinology and Metabolism 9 2856-2860. (doi:10.1210/jc.82.9.2856)

Marques RG, Morales MM \& Petroianu A 2009 Brazilian law for scientific use of animals. Acta Cirúrgica Brasileira 24 69-74. (doi:10.1590/S010286502009000100015 )

Matthews DR, Hosker JP, Rudenski AS, Naylor BA, Treacher DF \& Turner RC 1985 Homeostasis model assessment: insulin resistance and b cell function from fasting plasma glucose and insulin concentrations in man. Diabetologia 28 412-421. (doi:10.1007/BF00280883)

Meberg A \& Marstein S 1986 Smoking during pregnancy - effects on the fetal thyroid function. Acta Paediatrica Scandinavica 75 762-766. (doi:10.1111/j. 1651-2227.1986.tb10287.x)

Muller B, Zulewski H, Huber P, Ratcliffe JG \& Staub JJ 1995 Impaired action of thyroid hormone associated with smoking in women with hypothyroidism. New England Journal of Medicine 333 964-969. (doi:10.1056/ NEJM199510123331503)

Nagel G, Arnold FJ, Wilhelm M, Link B, Zoellner I \& Koenig W 2009 Environment tobacco smoke and cardiometabolic risk in young children: results from a survey in south-west Germany. European Heart Journal 30 1885-1893. (doi:10.1093/eurheartj/ehp180)

Newman MB, Shytle RD \& Sanberg PR 1999 Locomotor behavioral effects of prenatal and postnatal nicotine exposure in rat offspring. Behavioural Pharmacology 10 699-706. (doi:10.1097/00008877-199911000-00017)

Ng SP, Conklin DJ, Bhatnagar A, Bolanowski DD, Lyon J \& Zelikoff JT 2009 Prenatal exposure to cigarette smoke induces diet- and sex-dependent dyslipidemia and weight gain in adult murine offspring. Environmental Health Perspectives 117 1042-1048. (doi:10.1289/ehp.0800193)
Oliveira E, Moura E, Santos-Silva A, Fagundes A, Rios A, Abreu-Villaca Y, Nogueira-Neto JF, Passos MCF \& Lisboa PC 2009 Short and long-term effects of maternal nicotine exposure during lactation on body adiposity, lipid profile and thyroid function of rat offspring. Journal of Endocrinology 202 397-405. (doi:10.1677/JOE-09-0020)

Oliveira E, Pinheiro CR, Santos-Silva AP, Trevenzoli IH, Abreu-Villaça Y, Nogueira Neto JF, Reis AM, Passos MC, Moura EG \& Lisboa PC 2010 Nicotine exposure effects mother's and pup's nutriotional, biochemical and hormonal profile during lactation in rats. Journal of Endocrinology 205 159-170. (doi:10.1677/JOE-09-0430)

Park S, Ahn IS \& Kim da S 2010 Central infusion of leptin improves insulin resistance and suppresses beta-cell function, but not beta-cell mass, primarily through the sympathetic nervous system in a type 2 diabetic rat model. Life Sciences 86 854-862. (doi:10.1016/j.lfs.2010.03.021)

Peterson GL 1977 A simplification of the protein assay method of Lowry et al. which is more generally applicable. Analytical Biochemistry 83 346-356. (doi:10.1016/0003-2697(77)90043-4)

Rodrigues AL, Moura EG, Passos MCF, Dutra SCP \& Lisbo PC 2009 Postnatal early overnutrition changes the leptin signalling pathway in the hypothalamic-pituitary-thyroid axis of young and adult rats. Journal of Physiology 587 2647-2661. (doi:10.1113/jphysiol.2009.169045)

Santos-Silva AP, Moura EG, Pinheiro CR, Rios AS, Abreu-Villaça Y, Passos MC, Oliveira E \& Lisboa PC 2010 Neonatal nicotine exposure alters leptin signaling in the hypothalamus-pituitary-thyroid axis in the lete postnatal period and adulthood in rats. Life Sciences 87 187-195. (doi:10.1016/j.lfs. 2010.06.012)

Sinzato YK, Lima PHO, Santos CEM, Campos KE, Rudge MVC \& Damasceno DC 2008 Association of diabetes and cigarette smoke exposure on the glycemia and liver glycogen of pregnant Wistar rats. Acta Cirúrgica Brasileira 23 481-485. (doi:10.1590/S0102-86502008000600002)

Somm E, Schwitzgebel VM, Vauthay DM, Camm EJ, Chen CY, Giacobino JP, Sizonenko SV, Aubert ML \& Hüppi PS 2008 Prenatal nicotine exposure alters early pancreatic islet and adipose tissue development with consequences and the control of body weight and glucose metabolism later in life. Endocrinology 149 6289-6299. (doi:10.1210/en.2008-0361)

Somm E, Schwitzgebel VM, Vauthay DM, Aubert ML \& Hüppi PS 2009 Prenatal nicotine exposure and the programming of metabolic and cardiovascular disorders. Molecular and Cellular Endocrinology 304 69-77. (doi:10.1016/j.mce.2009.02.026)

Slotkin TA, Pinkerton KE, Garofolo MC, Auman JT, McCook EC \& Seidler FJ 2001 Perinatal exposure to environmental tobacco smoke induces adenylyl cyclase and alters receptor-mediated signaling in brain and heart of neonatal rats. Brain Research 898 73-81. (doi:10.1016/S0006-8993(01) 02145-X)

Stauffer CE 1975 A linear standard curve for the Folin Lowry determination of protein. Analytical Biochemistry $69646-648$.

Steinmaus C, Miller MD \& Howd R 2007 Impact of smoking and thiocyanate on perchlorate and thyroid hormone associations in the 2001-2002 national health and nutrition examination survey. Environmental Health Perspectives 115 1333-1338. (doi:10.1289/ehp.10300)

Toste FP, Moura EG, Lisboa PC, Fagundes AT, Oliveira E \& Passos MCF 2006 Neonatal leptin treatment programmes leptin hypothalamic resistance and intermediary metabolic parameters in adult rats. British Journal of Nutrition 95 830-837. (doi:10.1079/BJN20061726)

Trevenzoli IH, Valle MMR, Machado FB, Garcia RMG, Passos MCF, Lisboa PC \& Moura EG 2007 Neonatal hyperleptinemia programmes adrenal medulary function in adult rats: effects on cardiovascular parameter. Journal of Physiology 580 629-637. (doi:10.1113/jphysiol. 2006.126151)

Utiger RD 1998 Effects of smoking on thyroid function. European Journal of Endocrinology 138 368-369. (doi:10.1530/eje.0.1380368)

Von Kries R, Toschke AM, Koletzko B \& Slikker W 2002 Maternal smoking during pregnancy and childhood obesity. American Journal of Epidemiology 156 954-961. (doi:10.1093/aje/kwf128)

Wideroe M, Vik T, Jacobsen G \& Bakketeig LS 2003 Does maternal smoking during pregnancy cause childhood overweight? Paediatric and Perinatal Epidemiology 17 171-179. (doi:10.1046/j.1365-3016.2003. 00481.x) 
Williams CM \& Kanagasabai T 1984 Maternal adipose tissue response to nicotine administration in the pregnant rat: effects on fetal body fat and cellularity. British Journal of Nutrition 51 7-13. (doi:10.1079/BJN19840004)

World Health Organization 2009 WHO report on the global tobacco epidemic - Implementing smoke-free environments, pp 7-28. Bloomberg Pilanthropies.

Yu D, Berlin JA, Penning TM \& Field J 2002 Reactive oxygen species generated by PAH o-quinones cause change-in-function mutations in p53. Chemical Research in Toxicology 15 832-842. (doi:10.1021/tx010177m)

Zanardo V, Nicolussi S, Cavallin S, Trevisanuto D, Barbato A, Faggian D, Favaro F \& Plebani M 2005 Effect of maternal smoking on breast milk interleukin-1 $\alpha, \beta$-endorfin and leptin concentrations. Environmental Health Perspectives 113 1410-1413. (doi:10.1289/ehp.7702)

Zhang C, Cai S, Chen P, Chen JB, Wu J, Wu SJ \& Zhou R 2008a Inhibition of tumor necrosis factor- $\alpha$ reduces alveolar septal cell apoptosis in passive smoking rats. Chinese Medical Journal 121 597-601.
Zhang S, Xu N, Nie J, Dong L, Li J \& Tonh J 2008 b Proteomic alteration in lung tissue of rats exposed to cigarette smoke. Toxicology Letters 178 191-196. (doi:10.1016/j.toxlet.2008.03.014)

Zheng H, Liu Y, Huang T, Fang Z, Li G \& He S 2009 Development and characterization of a rat model of chronic obstructive pulmonary disease (COPD) induced by sidestream cigarette smoke. Toxicology Letters 189 225-234. (doi:10.1016/j.toxlet.2009.06.850)

Received in final form 16 December 2010

Accepted 17 January 2011

Made available online as an Accepted Preprint 17 January 2011 